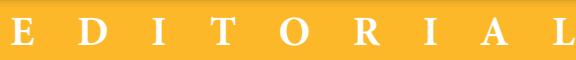

\title{
Caminando por los márgenes
}

\section{Wallking allong the margins}

J. Eduardo Sierra Nieto, Ester Caparrós Martín, Álvaro Pérez García, Noelia Alcaraz Salarirche, Manuel Fernández Navas, Mayka García García

Equipo Editorial

En lengua catalana, a los espárragos trigueros se los llama espàrrecs de marge; literalmente, espárragos de margen. Esta denominación se debe a que suelen crecer más animadamente en las orillas de los caminos, en especial en zonas secas y soleadas.

En los últimos años está sucediendo que, debido a las mejoras técnicas de la maquinaria agrícola, se aprovecha al máximo el terreno cultivable, de tal modo que casi no quedan márgenes. Como consecuencia, al menos en algunas zonas de Cataluña, la proliferación de los espàrrecs de marge ha disminuido notablemente; y todo en nombre, como decimos, de una mejora técnica aparejada al afán por exprimir la tierra y rentabilizar los cultivos. Esta es una situación que conocimos conversando hace algunos meses con el profesor José Contreras (UB), a propósito de la noticia de la creación de nuestra revista y, más concretamente, al darle a conocer su nombre: Márgenes, Revista de Educación de la Universidad de Málaga.

Este hecho que narramos nos pareció que tenía muchas posibilidades para presentarnos, precisamente porque elegimos el nombre de Márgenes para expresar nuestras aspiraciones, manteniendo un cierto paralelismo con estos espàrrecs de marge: colocarnos a uno de los lados del mainstream de las revistas de educación, para ofrecer la posibilidad de que otros modos de pensar, de investigar, de discutir, de comunicar, puedan proliferar; y hacerlo tratando de que las formas dominantes no lo arrasen todo.

Márgenes nace entonces con la intención de mantener una actitud crítica con ciertas prácticas y ciertos análisis, dando protagonismo a la teorización didáctica, a la reflexión pedagógica y a la praxis innovadora como pilares fundamentales de la educación. De forma complementaria, desde Márgenes mantenemos una posición firme y crítica ante la actual política editorial basada en los índices de

Márgenes
nace entonces
con la intención
de mantener
una actitud
crítica con ciertas
prácticas y ciertos
análisis, dando
protagonismo
a la teorización
didáctica, a
la reflexión
pedagógica y a la
praxis innovadora
como pilares
fundamentales de
la educación.


$\begin{array}{lllllllll}\text { E } & \text { D } & \text { I } & \text { T } & \text { O } & \text { R } & \text { I } & \text { A } & \text { L }\end{array}$

impacto, alineándonos con la Declaración de San Francisco de Evaluación de la Investigación.

Queremos señalar también el que la citada política editorial hegemónica está contribuyendo al auge de una visión de la educación amparada en la evaluación externa, alojada casi en exclusiva en enfoques cuantitativos y experimentalistas que, consecuentemente, infravaloran aproximaciones socio-constructivistas e interpretativas a los procesos y contextos educativos. En este caso, Márgenes se crea con el ánimo de dar visibilidad a otras propuestas metodológicas de corte cualitativo, las cuales encuentran actualmente pocos espacios para su publicación, difusión y discusión. En este punto, deseamos dejar claro que la cuestión no es meramente instrumental, ni se resuelve por la vía intermedia de los métodos mixtos. A nuestro modo de ver, la educación como ciencia social demanda unos métodos propios que se alejan de los experimentales.

Pese a lo anterior, somos conscientes de la incidencia que los citados criterios de calidad tienen para las carreras académicas y la estabilización laboral, especialmente de las y los jóvenes docentes e investigadores. Es por ello que nos proponemos trabajar para mejorar el impacto de la revista sin sacrificar por el camino nuestra preocupación por unos contenidos de calidad coherentes con nuestra filosofía educativa.

Márgenes, Revista de Educación de la Universidad de Málaga, quiere dar comienzo a su andadura con la publicación de un número 0 de carácter temático en el que se explora, desde diferentes perspectivas, el siguiente interrogante: “¿Hacia dónde va la formación del profesorado?”. Una cuestión que, como sabemos, es recurrente en nuestro campo y nunca terminará de responderse del todo; pues las necesidades y demandas que se le hacen a la educación van cambiando y con ellas las expectativas que se proyectan sobre el propio oficio docente.

Confiamos en que este número fundacional, que propone hasta doce textos en sus diferentes secciones, constituya un espacio rico para el intercambio y la discusión, y estamos convencidos de que así será.

¡Comenzamos!

Márgenes,
Revista de
Educación de la
Universidad de
Málaga, quiere
dar comienzo a su
andadura con la
publicación de un
número 0 de
carácter temático
en el que se
explora, desde
diferentes
perspectivas,
el siguiente
interrogante:
“¿Hacia dónde va
la formación del
profesorado?”

